\title{
Perception of parents on nursing support rendered to parents with neonates admitted to neonatal intensive care unit in a state hospital in Windhoek, Namibia
}

\author{
Hatupopi Saara Kerthu, Nghitanwa Emma Maano* \\ University of Namibia, Faculty of Health Sciences, School of Nursing, Department of Midwifery Science, Namibia
}

Received: February 19, 2019

DOI: $10.5430 / \mathrm{cns} . v 7 \mathrm{n} 4 \mathrm{p} 22$
Accepted: April 8, 2019

Online Published: September 4, 2019

\begin{abstract}
Neonatal Intensive Care Units (NICU) plays a major role in providing care for premature neonates, sick neonates or neonates require surgery very soon following delivery. The experience of being a parent of a baby in NICU is more stressful especially if there is a little support or no support rendered from the nursing staff. Parents need support from the nursing staff to gain knowledge and understanding about the neonate's illness, treatment measures and hospital rules. However, no studies about this issue have been conducted in Namibia. The aim of this study was to investigate the perception of parents related to the nursing support rendered by nurses to parents whose neonates were admitted to NICU at a state hospital in Windhoek, Namibia. A quantitative, cross sectional survey was used to identify and describe parents' perceptions related to the nursing support rendered by nurses to parents whose neonates were admitted to NICU. The study results indicated that the majority of the participants perceived that they got the good support from the nurses. However, not all parents received needed support from nurses which could increases their stress level. The findings of this study could be used to improve the parents support to reduce stress among parents and neonates and to promote positive coping with regard to the stressful situation of newborns hospitalization.
\end{abstract}

Key Words: Intensive care unit, Parent, Neonate, Intensive care unit, Nursing, Perception, Support

\section{INTRODUCTION}

Neonatal intensive care units (NICU) plays a major role in providing care for premature babies, sick babies or babies require surgery very soon following delivery. The experience of being a parent of a baby NICU is stressful especially if there is a little support or no support at all from the nursing staff. ${ }^{[1]}$ Having a premature or sick neonate adds additional stress to parents and the infant. In addition, parents are undergoing serious negative experiences that include parental anxiety, depression, and posttraumatic stress. ${ }^{[2]}$

Admission of premature or sick neonate's to NICU could pose emotional challenges, such as frustration, guilt, shock, sadness and anger that their neonate is suffering from a serious medical condition. Moreover, the admission of the neonate into the NICU causes challenges such as separation of the infant from parents which increases strain on the infant-parent relationship. ${ }^{[3]}$ Parents need support from the nursing staff to gain knowledge about their neonate's illness, treatment measures and the hospital rituals and rules. ${ }^{[4]}$ Furthermore, parents need information on how to best meet their newborn's needs, opportunity to provide care of their newborns, acknowledgement of their important responsibility as parents, and positive reinforcement about their parenting of

\footnotetext{
*Correspondence: Nghitanwa Emma Maano; Email: enghitanwa@unam.na; Address: University of Namibia, Faculty of Health Sciences, School of Nursing, Department of Midwifery Science, Namibia.
} 
their sick newborns. ${ }^{[5]}$ According to Turner et al., ${ }^{[6]}$ nursing support for parents with hospitalized babies could be divided into five categories which include, providing supportive communication, ongoing information, helping parents maintain their parental role by encouragement, positive feedback and appraisal, giving emotional support, and providing expert nursing care to the baby. Moreover, emotional and social support may also elicit from the nurses who are involved in the day to day management of their babies. A study conducted in Australia has alluded to the central role that nurses play in the care of sick infants. ${ }^{[7]}$ The above authors further stated that nurses can alleviate parental stress by establishing a caring relationship, sharing knowledge and information, paying attention to supporting parents psychologically and physically, involving parents in decision making and empowering parents in the care of their baby. However, the researchers could not find any study of this kind in Namibia.

\section{Objective}

The objectives of this study are to:

- Identify attitudes of the nurses related to information giving and communication towards the parents.

- Determine parent's perception of emotionally supportive behaviors by nurses when their neonates are admitted to NICU.

- Identify parent's perception of appraisal support while in NICU environment.

- Determine parent's perception of instrumental support given by nurses when their neonates are admitted in NICU.

\section{Methodology}

A quantitative, descriptive cross sectional study design was utilised during this study. The setting of the study was a NICU at a tertiary hospital in Windhoek; Namibia.The study population was 63 parents of neonates admitted to a NICU at a tertiary hospital in Windhoek, Namibia who agreed to participate in the study. Inclusion criteria for this study required parents to have a new-borns admitted to a NICU for more than 24 hours but less than 30 days. Parents should agree to participate in the study. The registered nurse in charge of the NICU assisted the researchers in identifying the participants. Due to the limited number of the population no sampling was carried out as, all parents of new-borns admitted or has been admitted to a NICU at a tertiary hospital in Windhoek, Namibia at the time of data collection over a period of 5 months (from January 2018 to May 2018) were included. The study was conducted in 5 months because of the limited funding as researchers fund this study on their own. During the 5 months 76 neonates were admitted at the neonatal ICU and met the study criteria. However, only 68 parents agreed to participate in the study whereby 5 parents participated in the pilot study and were excluded from the main study. Therefore, the study was conducted among 63 participants who agreed to participate.

Data was collected with the questionnaires developed by the researchers which consist of sociodemographic information of the respondents and the modified Nurse-Parent Support tool (NPST). The NPST is a 21-items Likert scale questionnaire that was developed by Miles, Brunssen, \& Carlson, ${ }^{[8]}$ to assess the type of nursing support that parents received during the hospitalization of their newborns. The items comprising the tool was grouped into four subscales: Information Giving and Communication Support, Emotional Support, Appraisal Support and Instrumental Support. The Likert scale responses are: 1-strongly disagree, 2-disagree, 3-undecided, 4-agree and 5-strongly agree. The questionnaire was translated to Oshiwambo and Afrikaans by the researchers and checked by a language expert for validity. Questionnaires were translated to these languages as they are commonly spoken languages in Windhoek. The translation of questionnaires was also necessary to ensure that participants understand the questions clearly. To ensure validity and reliability of the data collection tool, data collection tool was piloted with 5 parents with the neonates admitted in NICU who were excluded from the main study. Adjustments were made on the final data collection tool based on the piloting.

Data collection tool were administered by the researchers on the time agreed by the parents and the registered nurse in charge of the NICU. The parents were contacted in the unit by both researchers. With prior information of the study objectives and after signing the informed consent, the parents answered the instrument's questions by their filling out the questionnaire. The researchers were also present to clarify any questions raised by the participants. In all cases, the parents filled out the instrument in the neonatal unit, during a moment that did not interfere with care .The researchers explained the purposed of the study to the participants and confidentiality was ensured. Data were coded and analyzed by SPSS Version 25. Individual questionnaire were coded to avoid wrong entry and computed correctly. Descriptive statistics were used and results were expressed in the format of absolute frequency tables.

\section{Ethical issues}

Ethical approval was obtained from the Ministry of Health and Social Service in Namibia. Permission had also been obtained from the hospital where the study was conducted. To protect the respondents, the researchers sensibly observed each parent as they were coming to ensure each one of them 
was not stressed by completing the questionnaire. Participants were informed about the purpose of the study and written consent was obtained prior to participation in the study. Parents were assured that their participation was voluntary and results could not be traced back to them as they were not allowed to write their names. Respondents were informed that they could withdraw from the study at any time, and their refusal to participate would in not in any way affect the care that their neonates were receiving.

\section{RESUlts}

\subsection{Socio-demographic data of the respondents}

Sociodemographic data was collected which include age, educational background and marital status of participants as presented.

\subsubsection{Age of participants}

All respondents were female aged between 18 to 45 years no male parents participated in this study. The $49.3 \%(n=31)$ were aged 18 to 25 years followed $36.4 \%(n=23)$ respondents aged 26 to 35 years old. The age group of respondents aged 36 to 40 to 45 were $4.8 \%(n=6)$ and 41 to 45 were $4.8 \%(n=3)$. The summary of respondent's ages is depicted in Table 1.

Table 1. Age of participants

\begin{tabular}{lll}
\hline Age of participants & Frequencies (N) & Percentage (\%) \\
\hline $18-25$ & 31 & 49.3 \\
$26-35$ & 23 & 36.4 \\
$36-40$ & 6 & 9.5 \\
$41-45$ & 3 & 4.8 \\
Total & 63 & 100 \\
\hline
\end{tabular}

\subsubsection{Educational background}

As displayed in Table 2, in terms of educational achievements $49.2 \%(n=31)$ respondents had completed secondary school, $25.4 \%(\mathrm{n}=16)$ had completed primary education while $22.2 \%(n=14)$ have completed tertiary education, however $3.2 \%(\mathrm{n}=2)$ possess no education background.

Table 2. Educational background of the respondent

\begin{tabular}{lll}
\hline Educational & Frequency $(\mathbf{N})$ & Percentage $(\%)$ \\
\hline None & 2 & $3.2 \%$ \\
Completed primary education & 16 & $25.4 \%$ \\
Completed secondary education & 31 & $49.2 \%$ \\
Completed tertiary education & 14 & $22.2 \%$ \\
Total & 63 & $100 \%$ \\
\hline
\end{tabular}

\subsubsection{Marital status}

As shown in Table 3 most of respondents $(n=47), 74.60 \%$ were single and $26.40 \%(n=16)$ were married.
Table 3. Marital status of the respondents

\begin{tabular}{lll}
\hline Marital status & Frequency $(\mathbf{N})$ & Percentage $(\%)$ \\
\hline Single & 47 & 74 \\
Married & 16 & 26 \\
Total & 63 & 100 \\
\hline
\end{tabular}

\subsection{Information giving and communication support}

As shown in Table 4, respondents were asked to indicate the information regarding the information giving and communication support they get from the nurses. In this regard, information giving and communication support $60.3 \%(\mathrm{n}=$ 38) respondents agreed that nurses included them in discussion when decision is made and $11.1 \%(n=7)$ strongly agree. While $20.6 \%(n=13)$ of the respondents disagree, $3.2 \%(n=$ 2) strongly disagree and $4.8 \%(n=3)$ of respondents were undecided.

On the issue of whether nurses are telling the parents about changes or improvement in their neonate's condition $58.7 \%$ $(n=37)$ of respondents agreed that they were told about changes or improvement in their neonate's condition, while $14.3 \%(n=9)$ strongly agree. Respondents were also asked to indicate whether the nurses have taught them how to give care to their neonate's. In this regards $66.7 \%(n=42)$ agreed and $20.6 \%(n=13)$ strongly agree.

On the statement whether the nurses help the parents understand their neonate's behavior and reaction, $47.6 \%(\mathrm{n}=$ $30)$ have agreed $20.6 \%(n=13)$ strongly agree. Furthermore, parents were also asked to indicate whether the nurses would allow the parents to decide whether to stay or leave during medical procedure of the neonate whereby, $46.0 \%$ (n $=29)$ of the participants agreed and $15.4 \%(n=10)$ strongly agree. It was also found that $54.0 \%(n=34)$ of the participants agreed that nurses answered the parent's questions satisfactory or looked for someone who answers them as indicated by $20.6 \%(n=13)$ of the participants who strongly agreed. When assessing whether parents feels that nurses helped them to understand what procedures were performed to their neonates $60.3 \%(n=38)$ of the respondents agreed and $19.0 \%(n=12)$ strongly agree, $12.7 \%(n=8)$ disagree while $1.6 \%(n=1)$ strongly disagree and $6.3 \%(n=4)$ were undecided. Furthermore, $60.3 \%(n=38)$ respondents agreed that nurses helped to learn how to comfort their neonates during or after the clinical procedure and $17.5 \%(n=11)$ strongly agree. On the question whether nurses are helping the parents to know the names and roles of the staff caring for their neonates $38.1 \%(\mathrm{n}=24)$ agreed, $12.7 \%(\mathrm{n}=8)$ strongly agreed. However, $36.5 \%(n=23)$ disagree, $7.9 \%(n=5)$ strongly disagree and $4.8 \%(\mathrm{n}=3)$ were undecided. 
Table 4. Respondents on information giving and communication support

\begin{tabular}{|c|c|c|c|c|c|}
\hline Information giving and communication & Agree & $\begin{array}{l}\text { Strongly } \\
\text { agreed }\end{array}$ & Disagree & $\begin{array}{l}\text { Strongly } \\
\text { disagree }\end{array}$ & Undecided \\
\hline \multirow{2}{*}{$\begin{array}{l}\text { 1. Included me in discussion when decision is } \\
\text { made? }\end{array}$} & $(\mathrm{n}=38)$ & $(n=7)$ & $(\mathrm{n}=13)$ & $(n=2)$ & $(n=3)$ \\
\hline & $60.3 \%$ & $11.1 \%$ & $20.6 \%$ & $3.2 \%$ & $4.8 \%$ \\
\hline \multirow{2}{*}{$\begin{array}{l}\text { 2. Told me about changes/improvement in my } \\
\text { child's condition? }\end{array}$} & $(\mathrm{n}=37)$ & $(\mathrm{n}=9)$ & $(\mathrm{n}=14)$ & \multirow{2}{*}{ None } & $(\mathrm{n}=3)$ \\
\hline & $58.7 \%$ & $14.3 \%$ & $22.2 \%$ & & $4.8 \%$ \\
\hline \multirow{2}{*}{ 3. Taught me how to give care to my child? } & $(\mathrm{n}=42)$ & $(\mathrm{n}=13)$ & $(\mathrm{n}=6)$ & $(\mathrm{n}=1)$ & $(\mathrm{n}=1)$ \\
\hline & $66.7 \%$ & $20.6 \%$ & $9.5 \%$ & $1.6 \%$ & $1.6 \%$ \\
\hline \multirow{2}{*}{$\begin{array}{l}\text { 4. Help me understand my child's behavior } \\
\text { and reaction? }\end{array}$} & $(\mathrm{n}=30)$ & $(\mathrm{n}=13)$ & $(\mathrm{n}=12)$ & $(\mathrm{n}=3)$ & $(\mathrm{n}=5)$ \\
\hline & $47.6 \%$ & $20.6 \%$ & $19.0 \%$ & $4.7 \%$ & $7.9 \%$ \\
\hline \multirow{2}{*}{$\begin{array}{l}\text { 5. Let me decide whether to stay or leave } \\
\text { during medical procedure? }\end{array}$} & $(\mathrm{n}=29)$ & $(\mathrm{n}=10)$ & $(\mathrm{n}=17)$ & $(n=5)$ & $(\mathrm{n}=2)$ \\
\hline & $46.0 \%$ & $15.4 \%$ & $27.5 \%$ & $7.9 \%$ & $3.2 \%$ \\
\hline \multirow{2}{*}{$\begin{array}{l}\text { 6. Answered my questions satisfactorily or } \\
\text { found someone who could? }\end{array}$} & $(\mathrm{n}=34)$ & $(\mathrm{n}=13)$ & $(\mathrm{n}=10)$ & $(n=6)$ & $(n=6)$ \\
\hline & $54.0 \%$ & $20.6 \%$ & $15.9 \%$ & $9.5 \%$ & $9.5 \%$ \\
\hline \multirow{2}{*}{$\begin{array}{l}\text { 7. Helped me understand what has being done } \\
\text { to my child? }\end{array}$} & $(\mathrm{n}=38)$ & $(\mathrm{n}=12)$ & $(\mathrm{n}=8)$ & $(\mathrm{n}=1)$ & $(n=4)$ \\
\hline & $60.3 \%$ & $19.0 \%$ & $12.7 \%$ & $1.6 \%$ & $6.4 \%$ \\
\hline \multirow{2}{*}{$\begin{array}{l}\text { 8. Help me know how to comfort my child } \\
\text { during or after procedure. }\end{array}$} & $(\mathrm{n}=38)$ & $(\mathrm{n}=11)$ & $(\mathrm{n}=9)$ & $(\mathrm{n}=1)$ & $(n=4)$ \\
\hline & $60.3 \%$ & $17.5 \%$ & $14.3 \%$ & $1.6 \%$ & $6.4 \%$ \\
\hline \multirow{2}{*}{$\begin{array}{l}\text { 9. Helped me know the names and roles of the } \\
\text { staff caring for my child? }\end{array}$} & $(\mathrm{n}=24)$ & $(\mathrm{n}=8)$ & $(\mathrm{n}=23)$ & $(n=5)$ & $(n=3)$ \\
\hline & $38.1 \%$ & $12.7 \%$ & $36.5 \%$ & $7.9 \%$ & $4.8 \%$ \\
\hline
\end{tabular}

Table 5. Emotionally support

\begin{tabular}{llllll}
\hline Emotionally support & Agreed & $\begin{array}{l}\text { Strongly } \\
\text { agreed }\end{array}$ & Disagree & $\begin{array}{l}\text { Strongly } \\
\text { disagree }\end{array}$ & Undecided \\
\hline 1. Showed concern about my well-being and my & $(\mathrm{n}=34)$ & $(\mathrm{n}=8)$ & $(\mathrm{n}=13)$ & $(\mathrm{n}=3)$ & $(\mathrm{n}=6)$ \\
worries or concern? & $54.4 \%$ & $12.7 \%$ & $20.6 \%$ & $4.8 \%$ & $9.5 \%$ \\
$\begin{array}{l}\text { 2. Helped me talk about my feelings, worries, or } \\
\text { concerns? }\end{array}$ & $(\mathrm{n}=12)$ & $(\mathrm{n}=16)$ & $(\mathrm{n}=23)$ & & $(\mathrm{n}=13)$ \\
\hline
\end{tabular}

Table 6. Appraisal support

\begin{tabular}{|c|c|c|c|c|c|}
\hline Appraisal support & Agree & $\begin{array}{l}\text { Strongly } \\
\text { agree }\end{array}$ & Disagree & $\begin{array}{l}\text { Strongly } \\
\text { disagree }\end{array}$ & Undecided \\
\hline \multirow{2}{*}{ 1. Response to child's needs in timely fashion? } & $(\mathrm{n}=40)$ & $(\mathrm{n}=10)$ & $(\mathrm{n}=5)$ & \multirow{2}{*}{ None } & $(\mathrm{n}=8)$ \\
\hline & $63.5 \%$ & $15.9 \%$ & $7.3 \%$ & & $13.3 \%$ \\
\hline \multirow{2}{*}{ 2. Showed that they like my child? } & $(\mathrm{n}=32)$ & $(\mathrm{n}=10)$ & $(\mathrm{n}=1)$ & $(n=4)$ & $(\mathrm{n}=16)$ \\
\hline & $50.8 \%$ & $15.9 \%$ & $1.6 \%$ & $6.3 \%$ & $25.4 \%$ \\
\hline \multirow{2}{*}{ 3. Were sensitive to my child's special need? } & $(\mathrm{n}=43)$ & $(\mathrm{n}=8)$ & $(\mathrm{n}=4)$ & $(\mathrm{n}=1)$ & $(\mathrm{n}=7)$ \\
\hline & $68.3 \%$ & $12.7 \%$ & $6.3 \%$ & $1.6 \%$ & $11.1 \%$ \\
\hline \multirow{2}{*}{ 4.Encourage me to ask questions about my child } & $(\mathrm{n}=45)$ & $(\mathrm{n}=9)$ & $(\mathrm{n}=4)$ & \multirow{2}{*}{ None } & $(\mathrm{n}=5)$ \\
\hline & $71.4 \%$ & $14.3 \%$ & $6.3 \%$ & & $8.0 \%$ \\
\hline
\end{tabular}

\subsection{Emotionally support}

Table 5 presents the data regarding emotional support the parents get from the nurses. Half of respondents $52.4 \%$ agreed that nurses showed concern about their worries and concerns towards the parents with admitted neonates and $12.7 \%$ respondents strongly agree. Concerning whether nurses help the parents with neonates admitted to NICU to talk about Published by Sciedu Press their feelings $25.5 \%(\mathrm{n}=16)$ respondents strongly agree and $19 \%(\mathrm{n}=12)$ agreed, however about one third of respondents $34.9 \%(n=23)$ disagree and $20.6 \%(n=13)$ were undecided.

\subsection{Appraisal support}

Respondents were requested to indicate their views regarding appraisal support they got from the nurses. Regarding 
whether the nurses respond to neonate's needs on time, most of the respondents $63.5 \%(n=40)$ agreed that nurses responded to their neonates needs on time.Regarding whether nurses showed that they like neonates, more than half of the respondents, $50.8 \%(\mathrm{n}=32)$ agreed and $15.9 \%(\mathrm{n}=$ 10) strongly agreed respectively. Concerning the question whether nurses were sensitive to neonates special needs, more than a half of respondents $68.3 \%(n=43)$ agreed and $12.7 \%(n=8)$ strongly agree, however, $6.3 \%(n=4)$ of respondents disagree, $1.6 \%(n=1)$ strongly disagree and $11.1 \%(n=7)$ were undecided respectively. Regarding whether nurses encouraged parents to ask questions about their neonates, most of the respondents, $71.4 \%(n=71.4)$ agreed and $14.3 \%(n=9)$ strongly agree.

Table 7. Instrumental support

\begin{tabular}{|c|c|c|c|c|c|}
\hline Instrumental support & Agree & $\begin{array}{l}\text { Strongly } \\
\text { agree }\end{array}$ & Disagree & $\begin{array}{l}\text { Strongly } \\
\text { disagree }\end{array}$ & Undecided \\
\hline \multirow{2}{*}{ 1. Gave good care to my child? } & $(n=41)$ & $(\mathrm{n}=17)$ & $(\mathrm{n}=2)$ & \multirow{2}{*}{ None } & $(n=3)$ \\
\hline & $65.1 \%$ & $27.1 \%$ & $3.2 \%$ & & $4.7 \%$ \\
\hline \multirow{2}{*}{$\begin{array}{l}\text { 2. Allow me to be involved in my neonate's care } \\
\text { whenever possible? }\end{array}$} & $(\mathrm{n}=39)$ & $(\mathrm{n}=21)$ & $(\mathrm{n}=2)$ & \multirow{2}{*}{ None } & $(\mathrm{n}=1)$ \\
\hline & $61.9 \%$ & $33.3 \%$ & $3.2 \%$ & & $1.6 \%$ \\
\hline \multirow{2}{*}{ 3. Were optimistic about my child? } & $(\mathrm{n}=38)$ & $(\mathrm{n}=9)$ & $(\mathrm{n}=1)$ & $(\mathrm{n}=1)$ & $(\mathrm{n}=10)$ \\
\hline & $60.3 \%$ & $14.3 \%$ & $2.0 \%$ & $2.0 \%$ & $15.5 \%$ \\
\hline \multirow{2}{*}{$\begin{array}{l}\text { 4. Let me know I'm doing a good job in helping } \\
\text { my child }\end{array}$} & $(\mathrm{n}=37)$ & $(\mathrm{n}=14)$ & $(n=6)$ & $(\mathrm{n}=1)$ & $(\mathrm{n}=1)$ \\
\hline & $58.7 \%$ & $22.2 \%$ & $9.5 \%$ & $1.7 \%$ & $1.7 \%$ \\
\hline \multirow{2}{*}{ 5. Made me feel important as the parent? } & $(\mathrm{n}=35)$ & $(\mathrm{n}=16)$ & \multirow{2}{*}{ None } & $(n=6)$ & $(n=6)$ \\
\hline & $55.9 \%$ & $24.9 \%$ & & $9,6 \%$ & $9.6 \%$ \\
\hline
\end{tabular}

\subsection{Instrumental support}

On the statement whether nurses gave good care to the neonates, most of respondents $65.1 \%(\mathrm{n}=41)$ agreed and $27.0 \%(\mathrm{n}=17)$ strongly agree. The study shows that most of respondents $61.9 \%(n=39)$ agree that nurses allowed them to be involved in the care of their neonates whenever possible while $33.3 \%(n=21)$ strongly agree. When respondents were asked to specify whether nurses were optimistic about their neonates, more than a half of respondents $60.3 \%(n=38)$ agreed, while $14.3 \%(\mathrm{n}=9)$ strongly agree. The study shows that more than half $58.7 \%(n=37)$ of the respondents agreed that nurses let them know that they were doing a good job in helping their neonates, and only $22.2 \%(\mathrm{n}=14)$ who strongly agree. However $9.5 \%(n=6)$ of respondents disagree, $1.7 \%$ $(\mathrm{n}=1)$ undecided and $1.7 \%(\mathrm{n}=1)$ strongly disagree. More than a half of the respondents $55.9 \%(n=35)$ agreed that nurses made them feel important as parents and $24.9 \%(\mathrm{n}=$ 16) strongly agree. However, $9.6 \%(n=6)$ of the respondents were undecided, while $9.6 \%(n=6)$ strongly disagree.

\section{Discussion}

The current study reveals that, almost half of the respondents are young adults aged between 18 to 25 years followed by 26 to 35 years. These results confirmed by the Namibian Demographic and Health Survey ${ }^{[9]}$ outcome which reveals that in Namibia, the fertility rate was higher at 168/1,000 in women aged 20 to 29 .

Most of parent who participated in this study $74 \%$ were sin- gle and $16 \%$ were married. Current study show high rate of single parents, thus could be a possible explanation why no father participated in this study. Another possible interpretation might be from African cultural where women are considered as primary care giver to neonates, thus might influenced the absence of father participation. However, further study needs to be done to identify the importance of co-parenting and the cultural influence in care.

Information support includes the provision of advice; suggestions and sharing that parent could use to address the problem. Parents whose neonates admitted to a NICU mostly depend on the nurses to give them information and support about condition and care concerning their neonates. ${ }^{[10]}$ Effective communication between nurses and parents is a crucial supportive care, yet in this new and busy environment might be not adequate. The current study assessed the information giving and communication support between nurses and parents. When parents asked whether nurses gave them information and included them in discussion when any decisions are made concerning their neonates, more than half $60.3 \%$ of parents agreed. This implies that nurses paid attention to the parents and took time to inform them in all parts of the care given to their neonates. The manner in which the nurses informed the parents about the care of their neonates is an important factor helps the parents to bond with their neonates, thus relieve stress. In a study done by Orapiriyakul et al., ${ }^{[11]}$ it was reported that communication between nurses and parents assist early bonding between parents and neonates. According to 
Wigert, ${ }^{[10]}$ all parents agreed that nurses who communicate with the mothers by simple providing constant information and updating them on their baby health condition would help parents to understand their neonates health needs thus, eased anxiety. The results of current study is agreement with the findings of the study conducted in Sweden, were 25 mothers whose infants were admitted to NICU felt that they were supported and empowered to participate in their infants care by most of the nurses while few were feeling disempowered and unsupported by nurses. ${ }^{[12]}$ Studies has also identified that high demands placed on nurses, shortage of staffs often end in lack of time to communicate with parents. ${ }^{[13,14]}$

Emotionally supportive behaviors by nurses, it's associated with partaking life experience for instance, providing empathy, love, trust and caring. Parents emotional reactions to the NICU experience include disappointment, guilt, sadness, depression, anger, fear, anxiety and grief. ${ }^{[8,15]}$ Parents might also experience a feeling of helplessness due to the unexpected and traumatic birth experience, likely reducing her confidence in her role as a mother. ${ }^{[16]}$ It is vital for the nursing staff to recognize these parental traumas, and be able to provide required support. These include showing concern about parents well-being and responding to worries or concern. Moreover, it's also crucial to let parents talk about their feelings and worries. In this study, more than half of respondents agreed that nurses showed them concern about their worries. This implies that nurses not only cared about sick neonates but the NICU nurses cared about parents as well. Furthermore, Sargent ${ }^{[17]}$ found that among mothers with neonates in the NICU, emotionally support was the most important need to be fulfilled for them while their neonates were still hospitalized. Current study findings are in line with Reis ${ }^{[18]}$ who also reported that parents felt well taken care of, that the professionals' empathy assisted them interconnect, thus nurses conveyed feelings of security, trust and peace.

However during the current study when parents were asked whether nurses helped them to talk about their feelings, worries or concerns about one third $34.9 \%$ disagreed. Nurses did not take time from their busy schedule to listen to the parent's worries and concerns. Talking about parents worries other than the neonate's health, has a positive influence on the parents and could make them feel more relaxed. Hence, it became evident that it is not only the critically ill neonates who require to be taken care of, it is also essential to take care of the parent's emotional well being. In addition, HolditchDavis ${ }^{[19]}$ identified that parents were upset when nurses only paid attention on their sick babies rather than including parents emotionally well- being. The current study suggest a need for nurses in the NICU to become more aware of the needs and feeling of the mothers and to make a viable effort to reduce maternal stress levels through communication and empathy, whenever possible.

Appraisal support involves the provision of information that is useful for self-evaluation purpose for instance constructive feedback, affirmation and social comparison. The NICU practice creates an important challenge for nurses to integrate care that is directly supports the growth of the premature or sick neonate at the same time also focus on the mother-neonates attachment and supporting the parents as collaborators in their infant's care. ${ }^{[13]}$ Nurses have the capacity to increase parental self-esteem and confidence during their time in the NICU with their neonate's by encouraging them to visit as well as educating them how to care for their neonates. ${ }^{[20]}$ Most of respondents $63.5 \%$ agreed that nurses responded to need of their babies in timely fashion. Meaning despite the complex relations with staff, they felt supported and encouraged by availability of caring nursing staff and sensitivity toward their neonates special needs. Current study findings are in agreement with Zimmerman ${ }^{[21]}$ who found out that educating parents and encouraging them to take participation in child's care would have a countless impact not only on the level of care, but also their relation with a neonate, and thus prepares them to the further care after discharged.

There is an increase strain that placed on the neonates-parent relationship during the early separation of the neonates from both parents upon admission to the NICU. ${ }^{[3]}$ When the attachment is not established within the first few weeks after birth, or when there is an interruption in the attachment process, there is a higher risk of abuse and neglect of the baby in future. ${ }^{[2]}$ The authors demand the need for parents to be present in the NICU to engage in the care of their neonates, thus prevent the negative neuro-behavioural.

Current study results indicate that most of parents $61.9 \%$ agreed that they were involved in the care of neonates. Parents need to be involved in the care of their neonates spend some time with them, to take a participation, to feel that it is their neonates. Moreover, Reynolds ${ }^{[23]}$ identified that even a simple tasks which includes touching, performing simple hygiene for neonates is already determined as participation process, thus encourage parents. Family- centered care is intended to reassure the parents to take a part in the care planned and given to their neonates, and it also promote bonding. A study in Australia has alluded to the central role that nurses play in the care of sick neonates. ${ }^{[7]}$ Nurses can alleviate parental stress by establishing a caring relationship, sharing knowledge and information, paying attention to supporting parents psychologically and physically, involving parents in decision-making and empowering parents in the care of their baby. 
Furthermore literature has pointed out that visitation, holding, talking and skin to skin contact which is called Kangaroo mother's care are connected with best outcomes for neonates and parents when in hospital and after discharged or at home. ${ }^{[24]}$ It is vital that the NICU promote parent-neonate attachment by providing opportunity for the parents to stay, hold, talk, and bond with their neonate.

However, during the current study about one third of parents indicated that they were not involved in the care of their neonates. It is not surprising that women expressed feelings of isolation and rejection from their neonate's care. ${ }^{[25]}$ Similarly, Medina ${ }^{[25]}$ in their study stated that parents felt isolated and rejected regarding the care of their neonates. Some mothers further reported disappointment about missed out on some doings, which includes bath time, and reported feeling generally unwelcomed or as if they were in the way of nurses and staff. ${ }^{[25]}$ Current study findings are further in agreement with findings of study which identified that in spite of the fact that nurses inspire parents to take a part in the care of their neonates. ${ }^{[3]}$ Nurses face challenges, how to advocate the balance between a control over the situation from their side and involvement of the parents, finding a best excellent middle in this teamwork.

In the current study when parents were asked whether the nurses let them know if they were doing good job by helping their neonates. More than half $58.7 \%$ agreed that they are appreciated by nurses. Current study findings support the findings ${ }^{[26]}$ which identified that some of the parents responded that nurses pushed them to do something, for instance to hold a neonate or change a nappies from time to time. Although parents were scared, stressed and nervous, nurses informed them that they are doing good job and thus, made parents to relax a bit and feel much better.

\section{Conclusions}

The study results concluded that many parents with neonates admitted in NICU are young single mothers with secondary education status. The study reveals that parents perceived receiving positive support from the nurses working at the NICU in tertiary hospital in Namibia. The study conclude that parents are getting information giving support, emotional support, appraisal support and instrumental support from the nurses working in NICU. However, improvement is needed as some parents indicated that they were not receiving support from the nursing staff. Furthermore, the study unveil that mothers are mostly the caregivers on neonates in NICU as fathers were not available to participate in the study. The study results could be used to improve at ways how supportive information, emotional support, appraisal and instrumental are provided to reduce stress and improve coping among parents with regard to this stressful situation.

\section{Limitations}

The limitations of this study include the small sample size due to the limited number of neonates admitted in NICU during the study period. However, census sampling was used to include all parents, which met the study criteria. Therefore the result of this study could not be generalized .Furthermore, data collection was limited to one hospital in a specific geographical area mainly Windhoek. Due to financial burden, researchers were unable to conduct research in other NICU in other hospitals. The results of current study reflect the mother's perceptions only and do not address the specific emotions or support needs of fathers, as there was no neonatal father participated in the study

\section{CONFlicts OF INTEREST Disclosure}

The authors declare they have no conflicts of interest.

\section{REFERENCES}

[1] Treyvaud K, Lee KJ, Doyle LW, et al. Very preterm birth influences parental mental health and family outcomes seven years after birth. The Journal of Pediatrics. 2014; 164(3): 515-521. PMid: 24359937. https://doi.org/10.1016/j.jpeds.2013.11.001

[2] Feeley N, Genest C, Niela-Vilén H, et al. Parents and nurses balancing parent-infant closeness and separation: a qualitative study of NICU nurses' perceptions. BMC pediatrics. 2016; 16(1): 134. PMid: 27543122. https://doi.org/10.1186/s12887-016-0663-1

[3] Obeisat SM, Hweidi IM. Jordanian parental needs of critically ill infants in neonatal intensive care units. Journal of Research in Nursing. 2014; 19(4): 273-286. https ://doi .org/10.1177/1744987112 468444

[4] Hall SL, Ryan HP, Beatty J, et al. Recommendations for peer -to-peer support for NICU parents. Journal of Perinatology. 2015; 35: S9-s13 PMid: 26597805. https://doi.org/10.1038/jp.2015.143
[5] Franck LS, Cox S, Allen A, et al. Measuring Neonatal intensive care unit-related parental stress. Journal of Advanced Nursing. 2005; 49(6): 608-615. PMid: 15737221. https://doi.org/10.1111/j . 1365-2648. 2004.03336. $\mathrm{x}$

[6] Turner M, Chur-Hanse A, Winefied H. The neonatal nurses' view of their role in emotional support to parents and its complexities. Journal of Clinical Nursing. 2014; 23(31): 56-3165. PMid: 24575971. https://doi.org/10.1111/jocn. 12558

[7] Lam J, Spence K, Robert H. Parents' perception of nursing support in the neonatal intensive care unit. Neonatal Paeditric and Child Health Nursing. 2007; (10): 19-25.

[8] Miles M, Funk S, Carlson J. Parental stressor scale: Neonatal intensive care unit. Nursing Research. 1993; 42: 148-152. https: //doi.org/10.1097/00006199-199305000-00005

[9] Ministry of Health and Social Services. Namibia Demographic and 
Health Survey. Windhoek; 2013.

[10] Wigert H, Blom MD, Bry K. Parents' experiences of communication with neonatal intensive-care unit staff: an interview study. BMC Pediatrics. 2014; 14(1): 304. PMid: 25492549. https: //doi.org/10.1186/s12887-014-0304-5

[11] Orapiriyakul R, Jirapaet V, Rodcumdee B, et al. Struggling to get connected: the process of maternal attachment to the preterm infant in the neonatal intensive care unit. Thai Journal of Nursing Research. 2007; 11(4): 251. Available from: https ://www.researchgate.net/p rofile/Sujitra_Tiansawad/publication/236651854

[12] Flacking R, Ewald U, Nyqvist KH, et al. Trustful bonds: a key to "becoming a mother" and to reciprocal breastfeeding. Stories of mothers of very preterm infants at a neonatal unit. Social Science \& Medicine. 2006; 62(1): 70-80. PMid: 15992983. https: //doi.org/10.1016/j.socscimed.2005.05.026

[13] Johnson AN. Promoting maternal confidence in the NICU. Journal of Pediatric Health Care. 2008; 22(4): 254-257. PMid: 18590871. https://doi.org/10.1016/j.pedhc.2007.12.012

[14] Shahheidari M, Homer C. Impact of the design of neonatal intensive care units on neonates, staff and families: a systematic literature review. Journal of Perinatal and Neonatal Nursing. 2012; 26: 260166. PMid: 22843008. https : //doi.org/10.1097/JPN. Ob013e 318261ca1d

[15] Lau R, Morse CA. Parents' coping in the neonatal intensive care unit: a theoretical framework. Journal of Psychosomatic Obstetrics \& Gynecology. 2001; 22(1): 41-47. https ://doi.org/10.3109/ 01674820109049949

[16] Fegran L, Helseth S. The parent-nurse relationship in the neonatal intensive care unit context-closeness and emotional involvement. Scandinavian Journal of Caring Science. 2009; 23(4): 667-673. PMid: 19000088. https://doi.org/10.1111/j.1471-6712.2008.0 0659. $\mathrm{x}$

[17] Sargent AN. Predicters of needs in mothers with infants in the neonatal intensive care unit. Journal of Reproductive and Infant Psychology. 2009; 27(2): 195-205. https://doi/abs/10 .1080/0264683080 2350849
[18] Reis MD, Rempel GR, Scott SD, et al. Developing Nurse/Parent Relationships in the NICU Through Negotiated Partnership, Journal of Obstetric, Gynecologic \& Neonatal Nursing. 2010; 39(6): 679-680. PMid: 21039850. https ://doi.org/10.1111/j.1552 $-6909.2010 .01189 . \mathrm{x}$

[19] Holditch-Davis D, Miles MS. Mother's stories about their experiences in the neonatal intensive care unit. Neonatal Network. 2000; 19: 3, 13-21. PMid: 11949060. http://dx.doi.org/10.1891/0 730-0832.19.3.13

[20] Turan T, Basbakkal Z, Ozbek S. Effect of nursing interventions on stressors of parents of premature infants in Neonatal intensive care unit. Journal of Clinical Nursing. 2008; 17: 2856-2866. PMid: 18637857. https://doi.org/10.1111/j.1365-2702.2008.0 $2307 . \mathrm{x}$

[21] Zimmerman K, Bauersachs C. Empowering NICU Parents, International Journal of Childbirth Education. 2012; 27(1): 52.

[22] Trajkovski S, Schmied V, Vickers M, et al. Neonatal nurses' perspectives of family-centred care. Journal of Clinical Nursing. 2012; 21: 2480-2484. PMid: 22889445. https ://doi.org/10.1111/j.13 65-2702.2012.04138.x

[23] Reynolds LC, Duncan MM, Smith GC, et al. Parental presence and holding in the neonatal intensive care unit and associations with early neurobehavior. Journal of Perinatology. 2013; 33(8): 636. PMid: 23412640. https://doi.org/10.1038/jp. 2013.4

[24] Feeley N, Genest C, Niela-Vilén H, et al. Parents and nurses balancing parent-infant closeness and separation: a qualitative study of NICU nurses' perceptions. BMC Pediatrics. 2016; 16: 134. PMid: 27543122. https ://doi.org/10.1186/s12887-016-0663-1

[25] Medina IMF, Granero-Molina J, Fernández-Sola C, et al. Bonding in neonatal intensive care units: experiences of extremely preterm infants' mothers. Women and Birth. 2018; 31(4): 325-330. PMid: 29191725. https://doi.org/10.1016/j.wombi.2017.11.00 8

[26] Reis RS, Hino AA, Añez CR. Perceived stress scale: reliability and validity study in Brazil. J Health Psychol. 2010; 15(1): 107-14. PMid: 20064889. https://doi.org/10.1177/1359105309346343 